\title{
Editorial
}

\section{La Ciencia Peruana en el Bicentenario de la República}

En 1820 los franceses Píerre Joseph Pelletier y Joseph Bienaimé Caventou obtuvieron el alcaloide activo de la quina (la quinina), tres años después se creó la primera fábrica química que produjo sulfato de quinina. Los científicos peruanos de esa época no eran ajenos a esos descubrimientos, prueba de ello es el reporte en Anales Medicinales que el sulfato de quinina había sido preparado en el laboratorio por Agustín Cruzate, en 1827. Dicho compuesto era muy requerido por la industria farmacéutica de la época usado en el tratamiento del paludismo. La investigación en el extranjero de nuestros productos naturales casi siempre ha sido más numerosa y completa que la realizada en nuestro país, y esto ha sido una constante en nuestra vida republicana.

En los tiempos cercanos a nuestra independencia en el Perú las investigaciones eran llevadas a cabo por personas adineradas, quienes invertían parte de su fortuna y mucho de su tiempo en conocer los fenómenos de la naturaleza. No había una política de estado con respecto a las investigaciones científicas, pero sí había sociedades científicas que por entusiasmo se fundaban, pero luego, poco tiempo después, fenecían por el abandono de patrocinios o el abandono de sus socios. Un hecho notable sucedió en Arequipa un 10 de diciembre de 1821; se fundó la Academia Lauretana, gracias al esfuerzo de Evaristo Gómez Sánchez que su constitución señala su fin: "para promover, por cuantos medios estén a su arbitrio y facultad, el adelantamiento de las ciencias y artes, en la provincia y de mejorar la educación científica, política y moral de la juventud".

Con el transcurso de los años hubo algunas acciones de gobiernos y empresas en tratar de conocer mejor los recursos naturales de nuestro país y de paso impulsar la ciencia peruana. La acción más recurrida era traer a jóvenes científicos extranjeros al Perú, así llegaron Antonio Raimondi, José Eboli, Alfredo Bignon, Emmanuel Pozzi Scot, entre otros. No fue hasta 1856 cuando a pedido de Cayetano Heredia un grupo de los mejores estudiantes de medicina, uno de ellos fue Casimiro Ulloa, viajaron al mejor centro de medicina situado en París. Esta última práctica es la que hasta nuestros días continúa y predomina si analizamos las planas docentes de las diferentes universidades.

Hubo un periodo corto de algunos años cuando llegó al Perú el positivismo, que es una corriente filosófica que se inició en Europa a medianos del siglo 19 y comenzó su desaparición en 1907 cuando los profesores de Letras de la Universidad de San Marcos se alejan de ella hasta desaparecer pocos años después, pero que tuvo un gran impacto en los intelectuales y también en la política. Llegó al Perú casi después de finalizada la guerra con Chile. Fue relevante en la comprensión de la ciencia y de alguna manera impuso el pensamiento de orden, industrialización, desarrollo y progreso en las élites políticas. Como siempre pasa, esa filosofía vino y fue transformada por la propia idiosincrasia del peruano, de tal manera que casi quedó todo en tesis, discursos y debates y nunca se concretó realmente en un avance de la investigación científica aplicada en nuestro país. 
Años después de nuestra independencia en los países europeos las élites económicas y gobiernos si bien no estaban del todo convencidas, pero sí intuían los beneficios económicos que les podrían brindar las investigaciones científicas y de una manera u otra las comenzaron a apoyar. En el Perú y, claro, en Sudamérica, las luchas intestinales por el poder y la poca visión de país sumado a la pobreza de ideas progresistas de esas élites civiles y militares, que también ostentaban el poder político, tenían otros intereses más bien centrados, ya sea en explotar inmisericordemente los recursos naturales como el guano, salitre, minerales, caucho o en producción agroindustrial para la exportación, como azúcar o algodón, con mercados oligopólicos e incluso monopólicos.

En la historia se puede apreciar que los científicos peruanos han hecho, no muchas, pero sí algunas contribuciones científicas importantes, pero es más debido al entusiasmo, dedicación, trabajo individual y solitario que a un accionar institucionalizado ni mucho menos a una política de estado, son investigaciones hechas fuera de la periferia científica y que además cuando el investigador líder se retira no aparecen sus discípulos en un nivel igual o superior al maestro que los formó.

En algunos países desde hace siglos y en otros desde hace unas décadas se ha establecido la relación industria-gobierno-universidad (la triple hélice) mientras que el Perú solo está en el papel o en los discursos. Asimismo, en otros países hay variedad de patronatos, fundaciones y organizaciones constituidas por las élites económicas que apoyan con dinero diversas investigaciones científicas y tecnológicas, lo cual los lleva al desarrollo e innovaciones de diversos tipos, incrementando su oferta tecnológica y, claro, por supuesto, les proporciona ganancias económicas en retorno a su inversión. Con el devenir del tiempo esta diferencia de apoyo de las élites económicas al desarrollo científico entre los países llamados del primer mundo y Latinoamérica se va incrementando hasta llegar a los niveles actuales donde la brecha de conocimiento científico y tecnológico es sumamente grande y donde ni siquiera en el Perú somos capaces de producir vacunas, medicamentos ni insumos químicos básicos, entre otros bienes.

Finalmente, corresponde pues no solo establecer interacciones efectivas entre la academia, empresa, gobierno y sociedad civil, sino llevarlas a cabo y superar los problemas que seguro surgirán, con el fin de mejorar la calidad de vida de los peruanos y lograr una sociedad más culta, equitativa y democrática. Para que esto ocurra es necesario el compromiso de las élites económicas y la presión de la sociedad civil debidamente informada y organizada.

Mario Ceroni Galloso

Miembro de la Sociedad Química del Perú 